\title{
Urinary and dietary sodium and potassium associated with blood pressure control in treated hypertensive kidney transplant recipients: an observational study
}

\author{
Annie Saint-Remy ${ }^{1 *}$, Mélanie Somja ${ }^{2}$, Karen Gellner ${ }^{3}$, Laurent Weekers ${ }^{1}$, Catherine Bonvoisin ${ }^{1}$
} and Jean-Marie Krzesinski ${ }^{1}$

\begin{abstract}
Background: In kidney transplant (Kt) recipients, hypertension is a major risk for cardiovascular complications but also for graft failure. Blood pressure (BP) control is therefore mandatory. Office BP (OBP) remains frequently used for clinical decisions, however home BP (HBP) have brought a significant improvement in the BP control. Sodium is a modifiable risk factor, many studies accounted for a decrease of BP with a sodium restricted diet. Increased potassium intake has been also recommended in hypertension management. Using an agreement between office and home BP, the present study investigated the relations between the BP control in Kt recipients and their urinary excretion and dietary consumption of sodium and potassium.

Methods: The BP control defined by OBP $<140 / 90 \mathrm{mmHg}$ and HBP $<135 / 85 \mathrm{mmHg}$ was tested in 70 Kt recipients (mean age $56 \pm 11.5$ years; mean graft survival $7 \pm 6.6$ years) treated with antihypertensive medications. OBP and HBP were measured with a validated oscillometric device $\left(\mathrm{Omron} M \mathrm{M}^{\circledR}\right)$. The 24-hour urinary sodium ( $\mathrm{Na}+$ ) and potassium $(\mathrm{K}+)$ excretions as well as dietary intakes were compared between controlled and uncontrolled (in office and at home) recipients. Non parametric Wilcoxon Mann-Whitney Test was used for between groups comparisons and Fisher's exact test for frequencies comparisons. Pearson correlation coefficients and paired t-test were used when sample size was $>30$.

Results: Using an agreement between OBP and HBP, we identified controlled (21\%) and uncontrolled recipients (49\%). Major confounding effects susceptible to interfere with the BP regulation did not differ between groups, the amounts of sodium excretion were similar (154 \pm 93 vs $162 \pm 88 \mathrm{mmol} / 24 \mathrm{~h}$ ) but uncontrolled patients excreted less potassium ( $68 \pm 14$ vs $54 \pm 20 \mathrm{mmol} / 24 \mathrm{~h} ; \mathrm{P}=0.029$ ) and had significantly lower potassium intakes (3279 \pm 753 vs $2208 \pm 720 \mathrm{mg} / 24 \mathrm{~h} ; \mathrm{P}=0.009)$, associated with a higher urinary $\mathrm{Na}+/ \mathrm{K}+$ ratio. Systolic HBP was inversely and significantly correlated to urinary potassium $(r=-0.48 ; P=0.002)$, a positive but non significant relation was observed with urinary sodium $(r=0,30 ; P=0.074)$.

Conclusions: Half of the treated hypertensive Kt recipients remained uncontrolled in office and at home. Restoring a well-balanced sodium/potassium ratio intakes could be a non pharmacological opportunity to improve blood pressure control.
\end{abstract}

Keywords: Kidney transplantation, Office blood pressure, Home blood pressure, Sodium, Potassium, Urinary sodium/potassium ratio

\footnotetext{
* Correspondence: a.saintremy@ulg.ac.be

${ }^{1}$ Nephrology-Hypertension Unit, University Hospital of Liege, Liege, Belgium

Full list of author information is available at the end of the article
} 


\section{Background}

Hypertension (HT) is highly prevalent among kidney transplant recipients $(\mathrm{Kt})$, as 60 to $80 \%$ or more are concerned and the proportion of hypertensive patients receiving medication increases with time after kidney transplantation [1,2]. Hypertension is not only a major risk for cardiovascular (cv) complications but also for graft failure since a systolic blood pressure of $140 \mathrm{mmHg}$ or higher was associated with a significant graduated increase of graft failure [3]. This suggests a great importance to control blood pressure (BP). Although Office BP (OBP) remains certainly the most frequently method used for clinical decisions, complementary measurement techniques such as $24 \mathrm{~h}$ ambulatory blood pressure monitoring (ABPM) and home blood pressure (HBP) have brought a significant improvement in the identification of BP abnormalities and BP control in Kt recipients also $[4,5]$. These techniques appear to be more reproducible and superior in predicting target organ damage and cardiovascular events than OBP $[6,7]$

Many factors may be involved in the onset of HT in $\mathrm{Kt}$, among them the classical ones found in the general population such age, Body Mass Index (BMI), diabetes, kidney function, and those specifics to the transplantation, the donor's characteristics, the graft quality, immunosuppressive therapy with calcineurin inhibitors and corticosteroids.

Salt (sodium chloride) is a modifiable risk factor and although controversial, its relation with blood pressure and cardiovascular disease has been largely documented $[8,9]$. Excessive salt consumption concerns many countries, so World Health Organization has promoted a less than $6 \mathrm{~g}$ daily intake to prevent stroke and heart disease [10]. Increased potassium intake has also been recommended for prevention and treatment of hypertension, especially in those who are unable to reduce their intake of sodium [11,12].

As many Kt recipients with hypertension require several medications to reach target BP, it is of importance to add lifestyle modifications as a support contributing to the decrease of BP.

In the present study, we analyzed the quality of BP control and the relations between this control defined by office and home BP in Kt recipients treated with antihypertensive medications and their 24-h urinary sodium $(\mathrm{Na}+)$ and potassium $(\mathrm{K}+)$ excretion as well as their corresponding dietary intakes obtained by dietary recall.

\section{Methods}

\section{Study sample}

Two hundred and eleven Kt received a mail with the objectives of the study. Taking into account the early period after transplantation during which one many physiological and medical treatment modifications can arise, Kt recipients with a transplantation less than 1 year were excluded. On their next scheduled visit at the hospital, patients had the opportunity to receive more complete details on the study if necessary, those who agreed were invited to sign the informed consent. So a total of 78 patients with stable allograft function were included. As the study focuses on BP control under medications, 8 of these patients who were not treated with antihypertensive drugs were excluded.

The study received the approval from the Comité d'Ethique Hospitalo-Facultaire Universitaire de Liège.

\section{Blood pressure measurements}

BP measurements were first done at the hospital (office $\mathrm{BP})$. At the baseline visit, patients had to bring a $24 \mathrm{~h}$ urine collection and a completed report about what they ate and drunk during the urine collection period. After recording the clinical current conditions and the medications OBP was measured with an oscillometric automatic device OMROM $M 6^{\circledR}$ and adapted cuff size if necessary. OBP represents the mean of 3 consecutive measurements. If the 2 last measurements still varied from more than $5 \mathrm{mmHg}$, additional measurements were done.

\section{Home blood pressure}

After the baseline visit, all patients received explanations on how to perform correctly home BP measurements (HBP), with an OMROM M6 ${ }^{\circledR}$ that they have to bring back at the end of one week, usual recording period.

They had to record their HBP during 7 days with 2 measurements in the morning and 2 in the evening. HBP were averaged taking in account measurements from the day 2 to the day 7 [13].

\section{Hypertension criteria}

Hypertension was defined when office BP was $\geq 140$ and/ or $\geq 90 \mathrm{mmHg}$ ( $\geq 130$ and/or $\geq 80$ if diabetes) and when HBP was $\geq 135$ and/or $\geq 85 \mathrm{mmHg}$ ( $\geq 130$ and/or $\geq 80$ if diabetes) [13].

The antihypertensive treatment was not allowed to be changed during the study.

\section{Urine collection}

Two $24 \mathrm{~h}$ urine collections were available, the first one at the baseline visit and a second one when patients came back to the hospital at the end of the one week HBP recording period. Although accustomed to urine collection, patients were told again how to proceed.

Diuresis, sodium $/ 24 \mathrm{~h}(\mathrm{mmol} / 24 \mathrm{~h})$, potassium $/ 24 \mathrm{~h}$ $(\mathrm{mmol} / 24 \mathrm{~h})$ and creatinine $/ 24 \mathrm{~h}(\mathrm{~g} / 24 \mathrm{~h})$ were measured and sodium to potassium ratio $(\mathrm{Na} / \mathrm{K})$ was calculated. Proteinuria was also measured on this urine collected. 


\section{Dietary intake}

They also brought, as at the start of the study, with the second time $24 \mathrm{~h}$ urine collection, a detailed description of food and beverages consumed during urine collection, allowing the calculation of sodium and potassium intake during both $24 \mathrm{~h}$ periods. Quantitative analysis of the $24 \mathrm{~h}$ food records was done with the Belgian food table: NUBEL [14]. When a diet product was not referred in the NUBEL table, composition was extracted from the product itself if present or was analyzed with the composition table from the Paul Lambin Institute [15], or according to Souci et al. [16]. A particular attention was held to the bottled water consumed by patients because some of them were rich in sodium and to the water distribution whose composition could differ according to the living place of the patients. For a simple estimation of added salt, patients were asked if they used salt when cooking and/or when they ate.

\section{Statistical analysis}

Continuous data are presented as means ( \pm standard deviation) and frequencies as percentage.

Table 1 Characteristics of patients according to the control of Office Blood Pressure

\begin{tabular}{|c|c|c|c|}
\hline & $\begin{array}{c}\text { OBP }<140 \\
\text { and } \\
<90 \text { (mmHg) }\end{array}$ & $\begin{array}{c}\text { OBP } \geq 140 \\
\text { and/or } \\
\geq 90(\mathrm{mmHg})\end{array}$ & $\mathbf{P}$ \\
\hline $\mathrm{N}$ & 29 & 41 & \\
\hline Age (years) & $56 \pm 11$ & $57 \pm 11.7$ & 0.70 \\
\hline Graft survival (years) & $7.5 \pm 7.3$ & $6.4 \pm 6$ & 0.49 \\
\hline Office SBP (mmHg) & $126 \pm 9$ & $145 \pm 11$ & $<0.00001$ \\
\hline Office DBP (mmHg) & $78 \pm 8.5$ & $86 \pm 13$ & 0.004 \\
\hline Heart rate (beat/min) & $68 \pm 10$ & $69 \pm 12$ & 0.80 \\
\hline $\begin{array}{l}\text { Hemodialysis vintage } \\
\text { (years) }\end{array}$ & $3.0 \pm 5.4$ & $2.5 \pm 1.7$ & 0.56 \\
\hline $\mathrm{BMI}\left(\mathrm{kg} / \mathrm{m}^{2}\right)$ & $25.7 \pm 4.7$ & $25.8 \pm 4.7$ & 0.92 \\
\hline $\begin{array}{l}\text { Number of antihypertensive } \\
\text { drugs }\end{array}$ & $2.1 \pm 1$ & $2.1 \pm 1$ & 0.94 \\
\hline $\mathrm{GFR}(\mathrm{ml} / \mathrm{min})$ & $68.2 \pm 25$ & $63.1 \pm 25$ & 0.23 \\
\hline Calcineurin inhibitors N (\%) & $26(89.6)$ & $38(92.7)$ & 0.68 \\
\hline Prednisone (daily dose) & $4.7 \pm 1.8$ & $4.7 \pm 1.0$ & 0.87 \\
\hline \multicolumn{4}{|l|}{ Urinary excretion } \\
\hline Diuresis (ml) & $2439 \pm 846$ & $2593 \pm 968$ & 0.50 \\
\hline $\mathrm{Na}^{+}(\mathrm{mmol} / 24 \mathrm{~h})$ & $155 \pm 72$ & $176 \pm 90$ & 0.33 \\
\hline $\mathrm{K}^{+}(\mathrm{mmol} / 24 \mathrm{~h})$ & $66 \pm 23$ & $59 \pm 25$ & 0.28 \\
\hline $\mathrm{Na}^{+} / \mathrm{K}^{+}$ & $2.5 \pm 1.1$ & $3.2 \pm 1.2$ & 0.035 \\
\hline $\mathrm{NaCl}(\mathrm{g} / 24 \mathrm{~h})$ & $9.1 \pm 4.2$ & $10.3 \pm 5.3$ & 0.32 \\
\hline \multicolumn{4}{|l|}{ Diet intakes } \\
\hline $\mathrm{Na}^{+}(\mathrm{mg} / 24 \mathrm{~h})$ & $2289 \pm 942$ & $1868 \pm 679$ & 0.17 \\
\hline $\mathrm{K}^{+}(\mathrm{mg} / 24 \mathrm{~h})$ & $2900 \pm 780$ & $2243 \pm 773$ & 0.025 \\
\hline
\end{tabular}

According to the groups sample size, non parametric Wilcoxon Mann-Whitney Test was used for between groups comparisons (Tables 1 and 2) and the Fisher's exact test (two tailed) was used for percentage comparisons (Tables 1, 2 and 3). Pearson correlation coefficients, partial correlation coefficients (Table 4) and paired t-test

Table 2 Comparisons between controlled and uncontrolled patients- reference to office and home BP

\begin{tabular}{|c|c|c|c|}
\hline & $\begin{array}{l}\mathrm{OBP}<140 \\
\text { and }<90 \text { and } \\
\mathrm{HBP}<135 \\
\text { and }<85\end{array}$ & $\begin{array}{l}\mathrm{OBP} \geq 140 \\
\text { and } / \text { or } \geq 90 \text { and } \\
\mathrm{HBP} \geq 135 \\
\text { and } / \text { or } \geq 85\end{array}$ & $P$ \\
\hline
\end{tabular}

\begin{tabular}{lccc}
\hline $\mathrm{N}$ & 15 & 34 & \\
\hline Age (years) & $53.4 \pm 9.8$ & $56.8 \pm 11$ & 0.33 \\
\hline Graft survival (years) & $5.3 \pm 4$ & $6.3 \pm 6$ & 0.82 \\
\hline Nephrectomy (native & 1 & 5 & 0.65
\end{tabular}

kidney), (N)

\begin{tabular}{|c|c|c|c|}
\hline \multicolumn{4}{|l|}{ Donor } \\
\hline Age (years) & $\begin{array}{c}39.9 \pm 12.4 \\
{[17-54]} \\
\end{array}$ & $\begin{array}{c}42.7 \pm 16.5 \\
{[15-67]}\end{array}$ & 0.44 \\
\hline Hypertension, (N) & 3 & 5 & 0.69 \\
\hline Cadaveric, (N) & 14 & 34 & 0.31 \\
\hline Living, (N) & 1 & 0 & 0.31 \\
\hline Office SBP $(\mathrm{mmHg})$ & $125 \pm 9$ & $146 \pm 12$ & 0.000002 \\
\hline Office DBP (mmHg) & $77 \pm 8$ & $87 \pm 13$ & 0.004 \\
\hline Office heart rate (beat/min) & $67 \pm 9$ & $69 \pm 12$ & 0.78 \\
\hline Home SBP (mmHg) & $123 \pm 7$ & $141 \pm 10$ & 0.000001 \\
\hline Home DBP (mmHg) & $77 \pm 6$ & $85 \pm 11$ & 0.0005 \\
\hline Home heart rate (beat/min) & $68 \pm 5$ & $70 \pm 12$ & 0.81 \\
\hline Hemodialysis vintage (years) & $4.0 \pm 7$ & $2.6 \pm 2$ & 0.44 \\
\hline BMI $\left(\mathrm{kg} / \mathrm{m}^{2}\right)$ & $24 \pm 4.6$ & $26 \pm 4.9$ & 0.18 \\
\hline $\begin{array}{l}\text { Number of antihypertensive } \\
\text { drugs }\end{array}$ & $2.1 \pm 1$ & $2.1 \pm 1$ & 0.99 \\
\hline $\mathrm{GFR}(\mathrm{ml} / \mathrm{min})$ & $63.2 \pm 28$ & $61.5 \pm 21$ & 0.94 \\
\hline Calcineurin inhibitors N(\%) & $14(93)$ & $31(91)$ & 1.00 \\
\hline Cyclosporine & $2(13)$ & $14(41)$ & 0.045 \\
\hline Tacrolimus & $12(80)$ & $17(50)$ & \\
\hline Prednisone (daily dose) & $3.9 \pm 1.2$ & $4.7 \pm 1$ & 0.09 \\
\hline K+ (blood;mmol/l) & $\begin{array}{l}3.9 \pm 0.3 \\
{[3.1-4.5]} \\
\end{array}$ & $\begin{array}{l}4 \pm 0.4 \\
{[3.2-5]}\end{array}$ & 0.56 \\
\hline \multicolumn{4}{|l|}{ Urinary excretion } \\
\hline Diuresis (ml) & $2431 \pm 719$ & $2457 \pm 919$ & 0.90 \\
\hline $\mathrm{Na}^{+}(\mathrm{mmol} / 24 \mathrm{~h})$ & $154 \pm 93$ & $162 \pm 88$ & 0.60 \\
\hline $\mathrm{K}^{+}(\mathrm{mmol} / 24 \mathrm{~h})$ & $68 \pm 14$ & $54 \pm 20$ & 0.029 \\
\hline $\mathrm{Na}^{+} / \mathrm{K}^{+}$ratio $[\mathrm{Cl} 95 \%]$ & $\begin{array}{l}2.3 \pm 1.2 \\
{[1.6-3.1]}\end{array}$ & $\begin{array}{l}3.2 \pm 1.3 \\
{[2.7-3.6]}\end{array}$ & 0.052 \\
\hline $\mathrm{NaCl}(\mathrm{g} / 24 \mathrm{~h})$ & $9.1 \pm 5.4$ & $9.6 \pm 5.2$ & 0.60 \\
\hline \multicolumn{4}{|l|}{ Diet intakes } \\
\hline $\mathrm{Na}^{+}$(mg/24 h) & $2339 \pm 1067$ & $1766 \pm 695$ & 0.23 \\
\hline$\overline{\mathrm{K}^{+}}(\mathrm{mg} / 24 \mathrm{~h})$ & $3279 \pm 753$ & $2208 \pm 720$ & 0.009 \\
\hline
\end{tabular}


Table 3 Etiology of renal disease, classes of antihypertensive medications and proteinuria

\begin{tabular}{|c|c|c|c|}
\hline & $\begin{array}{l}\mathrm{OBP}<140 \\
\text { and }<90 \text { and } \\
\mathrm{HBP}<135 \\
\text { and }<85\end{array}$ & $\begin{array}{l}\mathrm{OBP} \geq 140 \\
\text { and } / \text { or } \geq 90 \text { and } \\
\mathrm{HBP} \geq 135 \\
\text { and/or } \geq 85\end{array}$ & $\mathbf{P}$ \\
\hline N & 15 & 34 & \\
\hline \multicolumn{4}{|l|}{$\begin{array}{l}\text { Etiology of renal } \\
\text { disease. } \mathrm{N}(\%)\end{array}$} \\
\hline Vascular disease & 0 & $1(3)$ & 1.00 \\
\hline Glomerulonephritis & $4(26.7)$ & $11(33.3)$ & 0.75 \\
\hline Polycystic kidney disease & $4(26.7)$ & $6(18.2)$ & 0.47 \\
\hline Diabetic nephropathy & $1(6.7)$ & $4(12.1)$ & 1.00 \\
\hline Tubulo intertitial disease & $1(6.7)$ & $6(18.2)$ & 0.22 \\
\hline Unknown & $5(33.3)$ & $5(15.2)$ & 0.13 \\
\hline \multicolumn{4}{|l|}{$\begin{array}{l}\text { Antihypertensive } \\
\text { drugs N (\%) }\end{array}$} \\
\hline Diuretics & $4(26.7)$ & $10(29)$ & 1.00 \\
\hline Thiazide and loop & 3 & 9 & 0.73 \\
\hline K-sparing & 1 & 1 & 0.51 \\
\hline Beta-blockers & $9(60)$ & $21(61.8)$ & 1.00 \\
\hline $\begin{array}{l}\text { Calcium-channel } \\
\text { blockers }\end{array}$ & $9(60)$ & $18(53)$ & 0.76 \\
\hline $\begin{array}{l}\text { Angiotensin converting } \\
\text { enzyme inhibitors }\end{array}$ & $5(33.3)$ & $11(32.3)$ & 1.00 \\
\hline $\begin{array}{l}\text { Angiotensin receptor } \\
\text { blockers }\end{array}$ & $4(26.7)$ & $5(14.7)$ & 0.43 \\
\hline $\begin{array}{l}\text { Centrally acting } \\
\text { sympathicolytics }\end{array}$ & $1(6.7)$ & $8(23.5)$ & 0.24 \\
\hline \multicolumn{4}{|c|}{ Proteinuria (mg/g creatinine) } \\
\hline$<40$ & $3(21.4)$ & $9(26.5)$ & 0.73 \\
\hline $40-200$ & $10(71.4)$ & 19 (55.9) & 0.35 \\
\hline$>200$ & $2(13.3)$ & $6(17.6)$ & 1.00 \\
\hline
\end{tabular}

were used when sample size was $>30$ (Table 5). Twosided $\mathrm{P}<0.05$ was considered as statistically significant.

Statistical analyses were performed with the Statistica ${ }^{\circledR}$ v10 software (www.Statsoft.com).

Table 4 Coefficients of partial correlation between urinary $\mathrm{Na}+$ and $\mathrm{K}+$ excretion and Home systolic blood pressure

\begin{tabular}{lcc}
\hline \multicolumn{1}{c}{$\begin{array}{c}\text { Pearson } \\
\text { correlations }\end{array}$} & $\begin{array}{c}\text { Partial correlation } \\
\text { coefficient }\end{array}$ & P \\
\hline $\mathrm{N}=49$ & & 0.074 \\
\hline $\begin{array}{l}\text { Home SBP with urinary } \\
\text { Na+ Controlled for: age, } \\
\text { BMl, smoking habit, } \\
\text { antirejection drugs and } \\
\text { urinary K+ }\end{array}$ & & \\
\hline $\begin{array}{l}\text { Home SBP with urinary } \\
\text { K+ Controlled for: age, } \\
\text { BMl, smoking habit, } \\
\text { antirejection drugs and } \\
\text { urinary Na+ }\end{array}$ & -0.48 & 0.002 \\
\hline
\end{tabular}

Table 5 Comparisons of electrolytes excretion and diet intakes 7 days apart

\begin{tabular}{lccc}
\hline & $\begin{array}{c}\text { 24 } \mathbf{h} \text { urine } \\
\text { collection } \\
\text { at baseline visit } \\
\text { mean } \pm \text { sd }\end{array}$ & $\begin{array}{c}\text { 24 } \mathbf{h} \text { urine } \\
\text { collection } \\
\text { 7 days later } \\
\text { mean } \pm \text { sd }\end{array}$ & $\mathbf{P}$ \\
\hline $\mathrm{N}=49$ & $2455 \pm 894$ & $2495 \pm 925$ & 0.60 \\
\hline Diuresis & $160 \pm 89$ & $157 \pm 72$ & 0.23 \\
\hline Urinary $\mathrm{Na}+(\mathrm{mmo} / 24 \mathrm{~h})$ & $58.2 \pm 19$ & $58.7 \pm 22$ & 0.69 \\
\hline Urinary $\mathrm{K}+(\mathrm{mmol} / 24 \mathrm{~h})$ & $2008 \pm 892$ & $2217 \pm 882$ & 0.86 \\
\hline Diet $\mathrm{Na}+(\mathrm{mg} / 24 \mathrm{~h})$ & $2659 \pm 896$ & $2814 \pm 873$ & 0.50 \\
\hline Diet $\mathrm{K}+(\mathrm{mg} / 24 \mathrm{~h})$ & & & \\
\hline
\end{tabular}

\section{Results}

Baseline characteristics of the treated hypertensive $\mathrm{Kt}$ are described in Table 6.

Mean age was $56( \pm 11.5)$ and patients were transplanted for 7 years $( \pm 6.6)$, the mean GFR (CockcroftGault formula) was 65.6 ( \pm 24$) \mathrm{ml} / \mathrm{min}$. Before kidney transplantation, they were all hemodialyzed with a mean time of 2.7 years. Obesity (BMI $\geq 30 \mathrm{~kg} / \mathrm{m}^{2}$ ) was present in $21 \%$ and diabetes frequency was $27 \%$, the majority (90\%) were transplantation induced diabetes. Patients were treated by a mean number of 2 antihypertensive drugs $( \pm 1)$. The $24 \mathrm{~h}$ mean urinary $\mathrm{NaCl}$ excretion was around $10 \mathrm{~g}$ indicating a high salt consumption equal to the one observed in the Belgian population and far from the $5 \mathrm{~g}$ recommended by the World Health Organization [17].

Sodium, potassium and control of office blood pressure The 70 patients with an antihypertensive treatment have been divided into 2 groups according the office BP

\section{Table 6 Baseline characteristics of patients}

\begin{tabular}{lc}
\hline $\mathrm{N}$ & Mean \pm sd [min-max] \\
\hline Men/women $(\mathrm{N})$ & 40 \\
\hline Age (years) & $56 \pm 11.5[33-76]$ \\
\hline Graft survival (years) & $7.0 \pm 6.6[1-25]$ \\
\hline Hemodialysis vintage (years) & $2.7 \pm 3.7[1$ month-7.9 y] \\
\hline GFR (ml/min) & $65.6 \pm 24[26-133]$ \\
\hline BMl (kg/m $\left.{ }^{2}\right)$ & $25.8 \pm 4.7[16-37]$ \\
\hline BMl $\geq 30$ & $9(13)$ \\
\hline Diabetes (N,\%) & $136 \pm 14[107-175]$ \\
\hline Current smokers (N,\%) & $83 \pm 12[50-108]$ \\
\hline Office SBP (mmHg) & $167 \pm 83[45-463]$ \\
\hline Office DBP (mmHg) & $62 \pm 24[25-134]$ \\
\hline $24 \mathrm{~h}$ urinary Na + (mmol) & $9.9 \pm 4.9[2.6-27]$ \\
\hline $24 \mathrm{~h}$ urinary K+ (mmol) & $2.9 \pm 1.2[0.8-6]$ \\
\hline NaCl (g/24 h) & \\
\hline Urinary Na+/K+ratio & \\
\hline
\end{tabular}


control. Uncontrolled patients were defined by an OBP $\geq 140$ and/or $90 \mathrm{mmHg}$ ( $\geq 130$ and/or $\geq 80$ if diabetes), so 41 patients (59\%) remained hypertensive despite the treatment while $29(41 \%)$ had their BP well controlled. Among uncontrolled patients, 56\% were men.

Comparisons between the 2 groups of controlled and uncontrolled office BP did not identify any statistical difference for age, graft survival, HD vintage, BMI, GFR, proportion of treated patients with calcineurin inhibitors or the mean number of antihypertensive drugs taken daily (Table 1). Logically, mean office systolic and diastolic BP of uncontrolled patients were significantly higher. Both groups had a similar salt consumption nearby $10 \mathrm{~g} /$ day. However, the urinary $\mathrm{Na} / \mathrm{K}$ ratio was significantly lower for patients with controlled BP than those uncontrolled (2.5 vs 3.2). Analysis of diet records shew that both groups did not differ in their salt consumption but controlled patients consumed higher amounts of potassium by regularly eating more fruits and vegetables, this could be in accordance with their lower observed $\mathrm{Na}+/ \mathrm{K}+$ ratio.

\section{Sodium, potassium and control of office and home blood pressure}

Did home BP bring any additional value to the association observed between office BP control and urinary excretion of sodium and potassium? To answer that question, the initial sample of 70 treated patients was classified not on the only OBP control but on the OBP and HBP control. So, uncontrolled patients were defined when their OBP was $\geq 140$ and/or $\geq 90 \mathrm{mmHg}$ ( $\geq 130$ and/or $\geq 80$ if diabetes) and their HBP was $\geq 135$ and/or $\geq 85 \mathrm{mmHg}$ ( $\geq 130$ and/or $\geq 80$ if diabetes), in other words when despite the treatment they remained hypertensive in the office and at home. Patients were defined as well controlled when OBP and HBP were lower than the above mentioned threshold criteria.

Controlled patients were $15(21 \%)$ and uncontrolled in both conditions were 34 (49\%) (Table 2). Masked hypertension (normal OBP but hypertension at home) was identified in 15 (21\%) and white coat hypertension (high OBP but normal BP at home) concerned 6 patients. As when considering the office $\mathrm{BP}$ only, the comparisons between controlled and uncontrolled patients both in office and at home did not underline significant differences for major parameters except for OBP and HBP of course. Donor's risk factors such as age or presence of hypertension did not differ. In both groups the majority were transplanted with a cadaveric kidney. Only 6 patients (one controlled and 5 uncontrolled) had a monolateral nephrectomy, so, among the 49 patients with true controlled or uncontrolled hypertension, 43 had their two native kidneys yet.
Classifying patients with that other method based on an agreement between office and home BP, generated also a group of uncontrolled patients whose urinary $\mathrm{Na}+$ excretion did not differ from the one of controlled but they significantly excreted less $\mathrm{K}+(\mathrm{P}=0.029)$. Their higher urinary $\mathrm{Na}+/ \mathrm{K}+$ ratio was just at the limit of statistical significance, however it seemed that they clearly consumed less potassium than controlled patients $(P=0.009)$, measured by the dietary recall technic. The same results were observed when the sodium/creatinine ratio was used.

There were no differences according the causes of renal insufficiency (Table 3) and the two groups were treated with similar proportions of the different classes of antihypertensive medications. Finally, proteinuria did not show any difference between groups.

It is important to note that the proportion of patients treated with diuretics (majorly thiazide and loop diuretics in both groups) did not differ between groups, $26.7 \%$ of controlled and $29.4 \%$ of uncontrolled. To verify any impact of the use of such diuretics on our observations mainly on the electrolytes excretion, we performed an internal comparison of OBP, HBP, urinary $\mathrm{Na}+$ and $\mathrm{K}+$ inside the two groups, controlled and uncontrolled, between those treated with or without a diuretic. No statistical difference for these parameters were observed between patients treated with or without diuretic drugs either in controlled or in uncontrolled patients. Moreover, let us remind that no change in the diuretic doses was allowed 1 month before the study and during the week of HBP measurement.

The observed association between uncontrolled BP and a lower potassium excretion has been tested by Pearson correlation on the 49 patients (true controlled and uncontrolled) among the 70 (Table 4).

Partial correlation coefficients have been calculated with systolic HBP by controlling age, BMI, antirejection drugs and smoking habit. Concerning the relation between urinary $\mathrm{Na}+$ excretion and systolic $\mathrm{HBP}$, the correlation has been also controlled for the urinary $\mathrm{K}+$. A positive correlation was observed $(0.30, \mathrm{P}=0.074)$ however the coefficient did not reach statistical significance. On the other hand, when controlled for urinary $\mathrm{Na}+$ excretion, a negative and highly significant relation was noted indicating an inverse association between the systolic HBP and excretion or intakes of potassium. However, no such results were observed with diastolic BP.

\section{Reproducibility of urinary sodium and potassium}

As two $24 \mathrm{~h}$ urine collections were available (at baseline visit and at the end of HBP recording) as well as food intakes during urine collection, a comparison of urinary and diet $\mathrm{Na}+$ and $\mathrm{K}+$ has been performed on the sample 
to assess the short term reproducibility of these parameters (Table 5).

Knowing that no change in the antihypertensive treatment occurred during the study, the paired comparisons between first and second urine collection did not show any statistical difference concerning urinary $\mathrm{Na}+$ and $\mathrm{K}+$ excretion as well as $\mathrm{Na}+$ and $\mathrm{K}+$ intakes which remained very similar into that period of time.

\section{Discussion}

\section{Blood pressure}

Controlling BP in hypertensive kidney transplant patients is mandatory to prevent cardiovascular complications and graft failure [18]. In most patients, several drugs are needed to reach a BP lower than $140 / 90 \mathrm{mmHg}$ (or 130/80). In such particular patients with a single functioning kidney, BP control can be difficult to reach because of a restricting therapy including immunosuppressive and corticosteroid medications. Our purpose was to analyze the daily practice control of $\mathrm{BP}$ by two methods (OBP and HBP) and the factors which could influence such control, especially looking for the potential contribution of non pharmacological intervention such to restore a well-balanced sodium/potassium ratio intakes in treated by antihypertenvive drugs Kt patients, as it was described in non transplanted hypertensive population $[19,20]$.

Indeed, in Kt patients with a stable kidney function, taking into account several determinants of BP, even though controlled and uncontrolled patients seemed to consume both a similar amount of salt, the controlled patients had significantly higher intakes of potassium, this could be associated with their lower $\mathrm{Na} / \mathrm{K}$ ratio compared to uncontrolled patients. On one hand, when controlled for age, BMI, antirejection drugs, smoking habit and $\mathrm{Na}+$ excretion, an inverse and significant relation was found between urinary potassium and HBP. On the other hand a positive but non significant relationship was observed between urinary sodium and HBP when controlled for $\mathrm{K}+$ excretion. As for many patients, outof-clinic BP are recommended for Kt patients [21,22]. In the present study, we favoured the use of two complementary BP measurement techniques i.e. office and home and defined controlled or uncontrolled BP when there was an agreement between both techniques. That classification of BP reinforced their truly status of normotensive or hypertensive treated patients taking into account the well known limitations of office BP and allowed the detection of masked and white coat hypertension [23].

The frequency of Kt patients remaining hypertensive despite a treatment requiring on average 2 or more drugs is too high, $58.6 \%$ based on OBP only but it decreases to $49 \%$ when based on both OBP and HBP (after excluding in the calculation of the proportion other forms such white-coat and masked hypertension).

Interpreting BP level in Kt patients is complex since many factors are susceptible to modify BP regulation.

Age, and BP status of donor, presence of native kidneys in recipients or number and kind of antihypertensive drugs did not differ between uncontrolled and controlled patients.

\section{Imunosuppressive medications}

Our controlled patients are mainly treated with tacrolimus (80\%) (Table 2) compared with uncontrolled ones (50\%) and this could partly explain the higher BP of the uncontrolled group as cyclosporine has been considered as a more hypertensive drug [24]. However in our study, on average, the number of antihypertensive drugs did not differ between the two BP control groups, moreover a comparison of BP (office and home) and of the number of antihypertensive drugs between patients treated by either cyclosporine or tacrolimus did not show any statistical difference. On average, our patients were transplanted for 5 (controlled) and 6 years (uncontrolled), it is known that incidence of hypertension increases with increasing time after transplantation, this is partly due to additional risk factors but also to the deleterious effects on the cardiovascular system caused by the sum of pre and posttransplant risk factors, so at this stage, it is difficult and even hazardous to attribute the uncontrolled BP to the only higher proportion of patients treated with cyclosporine rather than tacrolimus. Even if patients treated with tacrolimus were transplanted more recently than those treated with cyclosporin $(P=0.03)$, there were no significant differences according to age, GFR and time duration spent on hemodialysis.

Steroid treatment has been said to contribute to $15 \%$ in hypertension [25]. The frequencies of patients still treated with steroid were similar in cyclosporine and tacrolimus treated patients. Adherence to medications is also a key point in reaching BP target, all the patients questioned on their regularity in taking medications were particularly convinced by the importance of immunosuppressive and antihypertensive treatments regarding the graft protection.

\section{Urinary and dietary sodium and potassium}

Urinary $\mathrm{Na}+$ excretion is considered as representative of the dietary intakes in stable conditions. On average, in our study, controlled patients did not excrete less $\mathrm{Na}+$ than uncontrolled ones. The mean salt consumption was however between 9 and $10 \mathrm{~g}$ per day, with $87 \%$ who had salt consumption higher than $5 \mathrm{~g}$, so as in many countries, mean values exceeded largely the physiological 
needs [26] and this in spite of the fact that there are hypertensive treated by antihypertensive drugs.

Calculated sodium intakes were lower than urinary excretion. The difference can be explained by the lesser precision of the 24-h dietary recall intakes declared by patients recording their diet intake while they were collecting urine. Indeed, the real intakes were most certainly underestimated because the exact amount of food eaten by the patients was very difficult to know and moreover we could not assess the salt added in cooking and at table. However the patients were asked if they systematically added salt when cooking and/or at table, so $8(53 \%)$ controlled patients admitted to add salt against 22 (65\%) uncontrolled patients. Next the added salt, bread, high salted cheese and cooked meats and processed food were major diet sources of salt. Interestingly, the intakes and electrolytes excretions were reproducible on two occasions, 7 days apart. As sodium intake was less accurately quantified by dietary recall, a $24 \mathrm{~h}$ urine collection measuring sodium excretion would be better, after explaining the patient how to proceed.

On the contrary, the agreement between diet and urinary potassium seemed clearly better. This was documented in the study of Tasevska et al. who found a high correlation $(r=0.89)$ between dietary potassium and its urinary excretion in free living individuals [27].

Although all patients had potassium intakes lower that the $4700 \mathrm{mg}$ recommended [28], patients with controlled BP had on average higher potassium intakes with a diet richer in fruits and vegetables and contrary to what is generally said i.e. the high sodium consumers consume less potassium, in our population, there was no inverse relation between sodium and potassium intakes. The low consumption of potassium for several patients was not necessarily an individual's preference for salted food but was probably an habit they have kept when they were treated by hemodialysis, a situation in which strict limitations of potassium intakes are mandatory.

Randomized large-scale control trials on the effect of a modified sodium and potassium diet on blood pressure in late kidney transplant patients are lacking, however dietary sodium restriction $(80-100 \mathrm{mmol} /$ day or 1.8 to $2.3 \mathrm{~g} /$ day) is recommended to contribute to the cardiovascular burden management and also to limit the cyclosporin-induced hypertension caused by sodium retention in early post-transplantation [29].

Although the legendary salt controversy is still a hot topic [30-34], numerous studies favored a beneficial effect on BP, even sometimes modest, with reduction of salt intake and increasing potassium intakes. A drop of 3.5/2.5 mmHG with a $1.7 \mathrm{~g}$ increase of potassium intake and a drop of 5.2/3.7 $\mathrm{mmHg}$ with a decrease of $4.5 \mathrm{~g}$ of $\mathrm{NaCl}$ could be reached, however effects were larger in hypertensive than normotensive individuals [35].
Potassium supplementation was associated with a small but significant reduction in mean systolic and diastolic blood pressure ,-3.11 $\mathrm{mm} \mathrm{Hg}$ and $-1.97 \mathrm{~mm} \mathrm{Hg}$ respectively. Effects of treatment appeared to be enhanced in studies in which participants were concurrently exposed to a high intake of sodium[11]. The beneficial effect of $K$ on BP could be explained by a vasodilation action due to hyperpolarization of endothelial and vascular smooth muscle cell of the arterial wall [36]. Moreover, high potassium intake can decrease the salt sensitivity and also decrease the need for antihypertensive drugs [37].

Some observational studies did not find a correlation between salt intakes, estimated by $24-\mathrm{h}$ urinary $\mathrm{Na}$, and prevalence of hypertension or BP in $\mathrm{Kt}$ recipients with stable allograft function [38,39]. In these studies, measured office BP or hypertension defined by the prescription of antihypertensive medication, and the number of drugs were considered as a surrogate marker for severity of hypertension and no dietary analysis of sodium and potassium intakes was performed. In agreement with Prasad [40], we did not find any statistical difference of BP between patients treated with cyclosporine or tacrolimus and no difference in patients treated with or without a thiazide diuretic. However some methodological differences could explain our conclusions, indeed we defined the BP control on the basis of two measurement techniques and 24- $\mathrm{h} \mathrm{Na}+$ and $\mathrm{K}+$ measurements were associated to dietary intakes assessments. We observed a positive but non significant relation between urinary sodium and systolic home BP when confounding factors such as age, BMI, antirejection drugs, smoking habit and potassium excretion were controlled. We also observed a significantly negative correlation between systolic home BP and potassium excretion when age, BMI, antirejection drugs, smoking habit and sodium excretion were controlled. Therefore our results plead in favor of a possible efficient non pharmacological intervention by restricting sodium intakes and increasing potassium ones in Kt recipients. This was documented for sodium in the study of Keven et al. who measured a decrease in BP with daily intakes limited to the recommended levels between 80 and $100 \mathrm{mmol}$ [41]. In a very recent paper [42], van den Berg et al. found that sodium intake was positively and significantly associated with systolic and diastolic office BP in renal transplant recipients compared to healthy controls. Authors concluded that decreasing sodium intake to recommended amounts could decrease systolic BP by 4$5 \mathrm{mmHg}$. Conversely it was noted in CKD patients that high salt intake can increase proteinuria and ESRD risk [43]. In our study, proteinuria was not correlated with urinary $\mathrm{Na}$ excretion, but we have not tested the specific effect of a modification of such sodium intake on the proteinuria. This should be done to reinforce the 
argument for lowering sodium intake especially in hypertensive $\mathrm{Kt}$ patients who are proteinuric and exposed to higher cardiovascular and kidney disease progression risks.

Our uncontrolled patients had a higher $\mathrm{Na}+/ \mathrm{K}+$ ratio than controlled ones. The risk of subsequent cardiovascular disease related to a high $\mathrm{Na}+/ \mathrm{K}+$ ratio has been identified in adults with prehypertension, the effect of the ratio was even stronger than that of sodium or potassium alone [44]. It has to be confirmed in our Kt population with a prospective study.

Our study limitations concern the small size of the sample notably due to our selection criteria to define controlled and uncontrolled patients based on two measurement techniques in late $\mathrm{Kt}$ recipients. Cases of masked and white coat hypertension are not discussed in the present paper and have to be studied apart since interestingly, in the context of our study, we did not find a significant relation between sodium, potassium excretion and BP in those particular forms of hypertension (data not shown). Either confounding factors or other determinants of BP level in these patients have to be identified. Our study shows that measurements of $\mathrm{Na}+$ and $\mathrm{K}+$ intakes with a diet recall fulfilled by patients in a free way leads to limitations when data are compared with urinary excretion. We think that the main limitations came from patients who did not mentioned their complete intakes while they were collecting $24 \mathrm{~h}$ urines. Another problem came from the estimation of real amounts of food intakes which were not always accurately described by several patients, so we had to use standardized portions defined by "Poids et mesuresquantification standardisée des denrées alimentaires (Conseil Supérieur d'Hygiène, janvier 2005). The discrepancy between intakes and urinary $\mathrm{Na}+$ is higher than with $\mathrm{K}$, it can be explained by the fact that added salt was impossible to measure and that the amount of sodium in some processed foods was not mentionned, this was coupled with possible omissions from the patients in their recall diet document. The better correlation between intakes and urinary excretion of $\mathrm{K}+$ has been described in literature. Cooking methods are more conservative for potassium and added potassium sources are much more limited than those for sodium. It is possible that patients have been more reliable when they noticed their food consumption containing potassium rather than the one containing sodium. Obviously, those patients have kept habits from the time they were treated by dialysis when potassium intakes were strictly limited that is probably why they do not consume fruits and vegetables enough. We recognize that these considerations bear witness of a limited use of diet recall to calculate amounts of sodium and potassium. This has been mentionned in literature, so patients tend to underestimate their $\mathrm{Na}+$ intake by 30 to $50 \%$ while estimated $\mathrm{K}+$ intake better correlated with 24-h urinary excretion [45]. These observations are in favour of the use of $24 \mathrm{~h}$ urinary excretion provided that renal function and medications have to be taking in account.

Our study is crossectional so it gives a snapshot of a situation influenced by the complex and atypical risk factors profile of Kt patients mixing traditional, predisposing and associated to transplantation risk factors. Moreover, the factors which contribute to elevated BP vary between the early and late posttransplant periods, conditioning a continuous increase of the cardiovascular risk throughout time. Our patients have a mean transplantation duration of 7 years $( \pm 6.6)$, so in that late posttransplant period, next to the allograft function supervision, the management of the cardiovascular risk factors, among them hypertension, can beneficiate of the acquired experience with notably non pharmacological interventions in general population.

\section{Conclusions}

Our observational study shows that a large proportion of $\mathrm{Kt}$ recipients treated by drugs for hypertension present an uncontrolled BP using two different technics for BP measurements. Moreover, although both controlled and uncontrolled patients excreted a similar quantity of sodium in their urine, the uncontrolled patients excreted less potassium and had a higher $\mathrm{Na}$ $+/ K+$ ratio than controlled patients. The home systolic $\mathrm{BP}$, but not diastolic, was inversely and significantly correlated to urinary potassium when age, BMI, antirejection drugs, smoking habit and urinary sodium were controlled.

However, at this stage according to limited accuracy of diet recall, we cannot prove that in late kidney transplant recipients treated with antihypertensive drugs, there is a link of causality between the control of BP and the sodium/potassium balance intakes. To do this, a randomized control trial on a larger sample of patients is needed. However, our results support the idea of a potential relation between $\mathrm{BP}$ and the urinary and possibly the dietary sodium/potassium ratio in treated hypertensive uncontrolled patients with only mild CKD, suggesting so a non pharmacological opportunity to improve the BP control. This requires a validation of the diet recall technic and a randomized study to test this hypothesis especially in those who are in the mild form of kidney disease.

\section{Competing interests}

None of the authors has competing interests to declare.

\section{Authors' contributions}

ASR: conception, design, acquisition of data, analysis and interpretation. MS : analysis of diet data and interpretation. KG : acquisition of data, has given final approval of the version to be published. LW : substantial contribution to 
acquisition of data and their interpretation. CB : substantial contribution to acquisition of data and their interpretation. JMK: has revised the manuscript critically for important intellectual content. All authors read and approved the final manuscript.

\section{Aknowledgements}

We are grateful to Mrs Marie-Antoinette Graceffa and Mrs Michelle Focan, study nurses and Mrs Jacqueline Barbier, secretary, from the NephrologyHypertension Unit, for their useful contribution to the organization of the present study.

\section{Author details}

'Nephrology-Hypertension Unit, University Hospital of Liege, Liege, Belgium. ${ }^{2}$ Dietetics Unit, University Hospital of Liege, Liege, Belgium. ${ }^{3}$ Krankenhaus Düren-Medizinische Klinik II, Düren, Germany.

Received: 24 April 2012 Accepted: 22 September 2012

Published: 26 September 2012

\section{References}

1. First M: for the Transplant Therapy Outcomes Study Group. Study 1 : long-term cardiovascular risk after kidney transplantation. Transplant Rev 2003, 4:547.

2. Campistol J, Romero R, Paul J, Guttiérrez-Dalmau A: Epidemiology of arterial hypertension in renal transplant patients: changes over the last decade. Nephrol Dial Transplant 2004, 19(suppl 3):62-66.

3. Opelz G, Wujciak T, Ritz E: Association of chronic kidney graft failure with recipient blood pressure. Kidney Int 1998, 53:217-222.

4. Mancia G, Facchetti R, Bombelli M, Grassi G, Sega R: Long-term risk of mortality associated with selective and combined elevation in office, home, and ambulatory blood pressure. Hypertension 2006, 47:846-853.

5. Agena F, Dos Santos Prado E, Soarez Souza P, Da Silva GV, Lemos FB, Mion D Jr, Nahas WC, David-Neto E: Home blood pressure (BP) monitoring in kidney transplant recipients is more adequate to monitor $\mathrm{BP}$ than office BP. Nephrol Dial Transplant 2011, 26:3745-3749.

6. Sega R, Facchetti R, Bombelli M, Cesana G, Corrao G, Grassi G, Mancia G. Prognostic value of ambulatory and home blood pressures compared with office blood pressure in the general population: follow-up results from the Pressioni Arteriose Monitorate e Loro Associazioni (PAMELA) study. Circulation 2005, 111:1777-1783.

7. Stergiou GS, Bliziotis IA: Home blood pressure monitoring in the diagnosis and treatment of hypertension: a systematic review. Am J Hypertens 2011, 24:123-134.

8. Burnier M, Bochud M, Schmieder R: Dietary sodium intake and hypertension. European Society of Hypertension Scientific Newsletter. 2009. 10: $n^{\circ} 40$.

9. He F, Burnier M, MacGregor: Nutrition in cardiovascular disease: salt in hypertension and heart failure. Eur Heart J 2011, 32:3073-3080.

10. World Health Organization: Prevention of Cardiovascular Disease: Guidelines for assessment and management of cardiovascular risk. Geneva: World Health Organization; 2007

11. Whelton PK, He J, Cutler JA, Brancati FL, Appel LJ, Follmann D, Klag MJ: Effects of oral potassium on blood pressure. Meta-analysis of randomized controlled clinical trials. JAMA 1997, 277(20):1624-1632.

12. Frisoli T, Schmieder R, Grodzicki T, Messerli F: Beyond salt :lifestyle modifications and blood pressure. Eur Heart J 2011, 32:3081-3087.

13. Parati G, Stergiou GS, Asmar R, Bilo G, de Leeuw P, Imai Y, Kario K, Lurbe E, Manolis A, Mengden T, O'Brien E, Ohkubo T, Padfield P. Palatini P, Pickering TG, Redon J, Revera M, Ruilope LM, Shennan A, Staessen JA, Tisler A, Waeber B, Zanchetti A, Mancia G: ESH Working Group on Blood Pressure Monitoring. European Society of Hypertension Practice Guidelines for home blood pressure monitoring. J Hum Hypertens 2010, 24:779-785.

14. NUBEL-Table belge de composition des aliments, (Bruxelles, juin 2009, 5e edition) and with the NUBEL database. www.nubel.com).

15. Institut Paul Lambin: Table de composition des aliments. 1200 Bruxelles: 2004

16. Souci S, Fachmann W, Krout H: La composition des aliments, tableaux des valeurs nutritives. 5eth edition. Stuggart: Medpharm; 1994

17. World Health Organization: Diet, nutrition and the prevention of chronic disease. Report of a Joint WHO/FAO Expert Consultation. Geneva: WHO; 2003. technical report $n^{\circ} 916$
18. Opelz G, Döhler B: Collaborative Transplant Study. Improved long-term outcomes after renal transplantation associated with blood pressure control. Am J Transplant 2005, 5:2725-2731.

19. Appel L, Moore T, Obarzanek E, Vollmer W, Svetkey L, Sacks F, Bray G, Vogt $T$, Cutler J, Windhauser M, Lin P, Karanja N: A clinical trial of the effects of dietary patterns on blood pressure. DASH Collaborative Research Group. N Engl J Med 1997, 336:1117-1124.

20. He F, MacGregor G: Effect of modest salt reduction on blood pressure: meta-analysis of randomized trials. Implications for public health. J Hum Hypertens 2002, 16:761-770.

21. Agena F, Prado Edos S, Souza PS, da Silva GV, Lemos FB, Mion D Jr, Nahas WC, David-Neto E: Home blood pressure (BP) monitoring in kidney transplant recipients is more adequate to monitor BP than office BP. Nephrol Dial Transplant 2011, 26(11):3745-3749.

22. Covic A, Segall L, Goldsmith D: Ambulatory blood pressure monitoring in renal transplantation: should ABPM be routinely performed in renal transplant patients? Transplantation 2003, 76(11):1640-1642.

23. Prasad G, Nash M, Zaltzman J: A prospective study of the physician effect on blood pressure in renal-transplant recipients. Nephrol Dial Transplant 2003, 18:996-1000

24. Curtis J, Luke R, Jones P, Dietheim A: Hypertension in cyclosporine-treated renal transplant recipients is sodium-dependent. Am J Med 1988, 85:134-138.

25. Veenstra D, Best J, Hornberger J, Sullivan SD, Hricik DE: Incidence and longterm cost of steroid-related side effects after renal transplantation. Am J Kidney Dis 1999, 33:829-839.

26. Brown I, Tzoulaki I, Elliott P: Salt intakes around the world: implications for public health. Int J Epidemiol 2009, 38:791-813.

27. Tasevska N, Runswick S, Bingham S: Urinary potassium is as reliable as urinary nitrogen for use as a recovery biomarker in dietary studies of free living individuals. J Nutr 2006, 136:1334-1340.

28. U.S. Department of Health and Human Services, US Department of Agriculture. Sodium and Potassium: Dietary Guidelines for Americans 2005. Chapter 8. 6th Edition. U.S. Department of Health and Human Services and U.S. Department of Agriculture. Washington, DC: U.S. Government Printing Office; 2005. www.health.gov/dietaryguidelines/dga2005/ document/pdf/Chapter8.pdf.

29. Chadban S, Chan M, Fry K, Patwardhan A, Ryan C, Trevillian P, Westgarth F: CARI. The CARI guidelines Nutritional management of hypertension in adult kidney transplant recipients. Nephrology 2010, 15:S56-S61.

30. He F, MacGregor G: A comprehensive review on salt and health and current experience of worldwide salt reduction programmes. J Hum Hypertens 2009, 23:363-384.

31. Stolar-Skrzypek K, Kuznetsova T, Thiis $L$, Tikhonoff, et al: fatal and nonfatal outcomes, incidence of hypertension and blood pressure changes in relation to urinary sodium excretion. JAMA 2011, 305(17):1777-1785.

32. Ritz E: Salt and hypertension. Nephrology 2010, 15:49-52.

33. Mimran A, du Cailar G: Dietary sodium: the dark horse amongst cardiovascular and renal risk factors. Nephrol Dial Transplant 2008, 23:2138-2141.

34. Chioléro A, Würzner $\mathrm{G}$, Burnier M: Renal determinants of the saltsensitivity of blood pressure. Nephrol Dial Transplant 2001, 16:452-458.

35. Geleijnse JM, Kok FJ, Grobbee DE: Blood pressure response to changes in sodium and potassium intake: a metaregression analysis of randomised trials. J Hum Hypertens 2003, 17:471-480.

36. Haddy $F$, Vanhoutte $P$, Feletou M: Role of potassium in regulating blood flow and blood pressure. Am J Physiol Regul Integr Comp Physiol 2006, 290:R546-R552.

37. Adrogué $\mathrm{H}$, Madias $\mathrm{N}$ : Sodium and potassium in the pathogenesis of hypertension. N Engl J Med 2007, 356:1966-1978.

38. Moeller T, Buhl M, Schorr U, Distler A, Sharma AM: Salt intake and hypertension in renal transplant patients. Clin Nephrol 2000, 53(3):159-163.

39. Prasad G, Huang M, Nash M, Zaltzman: Role of dietary salt intake in posttransplant hypertension with tacrolimus-based immunosuppression. Transpl Proc 2005, 37:1896-1897.

40. Prasad G, Huang M, Nash M, Zaltzman: The role of dietary cations in the blood pressure of renal transplant recipients. Clin Transplant 2006, 20(1):37-42. 
41. Keven K, Yalçin S, Canbakan S, Kutlay S, Sengül S, Erturk S, Erbay B: The impact of daily sodium intake on posttransplant hypertension in kidney allograft recipients. Transplant Proc 2006, 38:1323-1326.

42. Van den Berg E, Geleijnse J, Brink E, Van Baak M, Homan Van Der Heide J, Gans R, Navis G, Bakker S: Sodium intake and blood pressure in renal transplant recipients. Nephrol Dial Transplant 2012, 27(8):3352-3359. doi:10.1093/ndt/gfs069.

43. Vegter S, Perna A, Postma M, Navis G, Remuzzi G, Ruggenenti P: Sodium intake, ACE inhibition, and progression to ESRD. J Am Soc Nephrol 2012, 23:165-173.

44. Cook N, Obarzanek E, Cutler J, Buring J, Rexrode KM, Kumanyika SK, Appel $\sqcup$, Whelton PK: Trials of Hypertension Prevention Collaborative Research Group. Joint effects of sodium and potassium intake on subsequent cardiovascular disease. Arch Intern Med 2009, 169(1):32-40.

45. Leiba A, Vald A, Peleg E, Shamiss A, Grossmann E: Does dietary recall adequately assess sodium, potassium, and calcium intake in hypertensive patients? Nutrition 2005, 21(4):462-466.

doi:10.1186/1471-2369-13-121

Cite this article as: Saint-Remy et al.: Urinary and dietary sodium and potassium associated with blood pressure control in treated

hypertensive kidney transplant recipients: an observational study. $B M C$ Nephrology 2012 13:121.

\section{Submit your next manuscript to BioMed Central and take full advantage of:}

- Convenient online submission

- Thorough peer review

- No space constraints or color figure charges

- Immediate publication on acceptance

- Inclusion in PubMed, CAS, Scopus and Google Scholar

- Research which is freely available for redistribution 